The relations of child adiposity with parent-to-child and parent-to-parent hostility

\author{
Michael F. Lorber ${ }^{1 *}$, Mandi L. White-Ajmani ${ }^{1}$, Denise Dixon ${ }^{2}$, Amy M. S. Slep $^{1}$, \& \\ Richard E. Heyman ${ }^{1}$ \\ ${ }^{1}$ New York University \\ ${ }^{2}$ Suffolk Health Psychology Services, PLLC
}

This is an Accepted Manuscript of an article published by Taylor \& Francis in Psychology \& Health on May 22, 2017, available online:

http://www.tandfonline.com/10.1080/08870446.2017.1336238

This work was supported by National Institute of Dental and Craniofacial Research [DE019537]. 


\begin{abstract}
Objective: Investigate (1) the association of child adiposity with parent-to-child and parent-to-parent hostility, (2) the mediation of these associations by dietary behaviours, and (3) moderation by gender.

Design: One hundred thirty-five couples with 6- to 14-year-old children completed measures of emotional and physical aggression, overreactive discipline, and child diet. Parent-toparent hostility was also coded from laboratory observations.

Main Outcome Measure: Child adiposity was a combination of body mass index and waist-to-hip ratio.

Results: Mother-to-child hostility was associated with child adiposity. This association was concentrated in boys and was not significantly explained by child dietary factors. Motherto-father hostility was not significantly associated with boys' or girls' adiposity. Girls' adiposity was not significantly associated with family hostility. Fathers' hostility was not linked to child adiposity.
\end{abstract}

Conclusion: This is the first study to take a family-level approach to understanding the relation of hostility to child adiposity by examining relations among adiposity and both mothers' and fathers' hostility directed toward one another and toward their children. Our findings highlight the potential role played by mothers' emotional hostility in boys' adiposity and suggest that, if this role is further substantiated, mother-son emotional hostility may be a promising target for the prevention of child obesity.

Keywords: child obesity, adiposity, hostility, aggression, parenting, IPV. 


\section{The relations of child adiposity with parent-to-child and parent-to-parent hostility}

Child adiposity — degree of body fat — is a major public health concern. At high levels of adiposity, children are classified as obese, usually based on meeting or exceeding the $95^{\text {th }}$ percentile of gender- and age-adjusted body mass index (BMI). Obesity affects approximately 17\% of all U.S. children aged 2-19 years old (Ogden, Carroll, Kit, \& Flegal, 2012). The associated medical (Daniels, 2009), mental health (Falkner et al., 2001), cognitive (Li, Dai, Jackson, \& Zhang, 2008), and social (Lumeng et al., 2010) costs are numerous, high, and appearing at increasingly younger ages (Daniels, 2009).

High child adiposity is a multifactorial problem (Fiese \& Bost, 2016). Some of the principal behavioural explanations have unsurprisingly focused on behaviours that tilt the caloric intake-expenditure ratio toward the former. Highly caloric diets, sedentary behavior, and lack of physical activity are particularly well established predictors of obesity (Saldanha-Gomes et al., 2016; Shroff et al., 2014). Family environmental factors that directly relate to energy balance have also proved important (e.g., child feeding practices; Birch, 2006). Yet other family factors that are not as obviously tied to energy balance may also play important roles in adiposity, as has more recently become apparent (e.g., overall quality of mother-child relationships; Anderson, Gooze, Lemeshow, \& Whitaker, 2011). Along this line of inquiry, several studies have begun to document the links between hostile family behaviours and child or adolescent adiposity (Boynton-Jarrett, Fargnoli, Suglia, Zuckerman, \& Wright, 2010; Gooding, Milliren, Austin, Sheridan, \& McLaughlin, 2015). It is on these links that we focus in this article.

In the present investigation, we evaluate the associations of hostile family behaviours with child adiposity, as well as dietary pathways that may explain such associations. The overarching conceptual framework was the risky families model (RFM; Repetti, Taylor, \& 
Seeman, 2002), a process model in which risky family social environments (e.g., those marked by conflict and aggression) are thought to cause a host of biological, emotional, and behavioural disturbances that lead to mental and physical health problems via risky health behaviours. It is a broad framework that is meant to apply to multiple health outcomes and that accommodates micro theories to explain specific links.

We focus on family hostility - a collection of behaviours including physical and psychological or emotional aggression, criticism, rejection, and other related forms of antagonism - as it is a particularly prevalent and chronic stressor in the lives of children. To illustrate, nearly $90 \%$ of the community sample of two-parent families with young children in Slep and O’Leary (2005, p. 441) "reported that some partner physical aggression, some parent physical aggression, or both occurred in the past year, and nearly one third reported at least one type of severe aggression (e.g., beat up, choked)." Moreover, hostile family behaviour is remarkably stable over time (Lorber \& O’Leary, 2012; Maguire-Jack, Gromoske, \& Berger, 2012).

The results of recent research suggest that various forms of parent-to-child and parent-toparent emotional aggression may confer risk for increased adiposity. The association between adiposity in adulthood and physical abuse in childhood is well documented (see Midei \& Matthews, 2011), but less attention has been given to how such experiences relate to adiposity as it is developing in childhood and adolescence. A few studies have examined adolescent adiposity, finding that childhood physical abuse predicts general adolescent overweight (BMI $\geq$ 90th percentile; Hussey, Chang, \& Kotch, 2006), higher BMI (Gooding, 2015), and increased waist circumference (Danese et al., 2011); when coupled with neglect, physical abuse also predicted higher adolescent BMI in Shin and Miller (2012). In contrast, Schneiderman, Mennen, 
Negriff, and Trickett (2012) reported an unexpected inverse association of physical abuse victimisation and obesity in adolescent girls. In two studies with younger children, Burke et al. (2011) showed that overall adverse childhood experiences (including emotional, physical, and sexual abuse, along with other non-abusive stressors) predicted greater BMI in 8-year-olds, but Whitaker et al. (2007) found no relation between preschoolers' obesity and either corporal punishment or psychological/emotional (e.g., name calling; threats) parent-to-child aggression. Intimate partner violence (IPV) may also play a role in child adiposity. Mothers' experience of chronic physical, sexual, or restrictive IPV from their partners predicted elevated obesity risk for 5-year-olds, especially girls (Boynton-Jarrett et al., 2010), and predicted consistently overweight and obese body mass trajectories among early adolescents, particularly boys (Jun et al., 2012). However, Rivas (2013) found no IPV-BMI association in preschoolers. Despite considerable evidence showing that women perpetrate IPV acts as often as men do (Slep \& O'Leary, 2005), the contributions of both mothers' and fathers' perpetration of IPV to child adiposity has not been studied, nor has the contribution of father-mother or father-to-child hostility to child adiposity.

\section{Entanglement of the influence of multiple facets of family hostility}

Family hostility consists of multiple interrelated components. If a child experiences one form of hostility (e.g., parent-to-child aggression), he or she has likely also experienced other forms (e.g., parental IPV). To illustrate, Slep and O'Leary (2005), using a representative community sample, found that nearly all of those who reported some form of parental physical IPV also reported parent-to-child physical aggression. Because these different forms of family hostility overlap considerably, a significant finding for one form may simply be a marker for the direct influence of another form, conflated with the first. For example, a significant finding for 
an association between parental IPV and child adiposity may actually be due to the causal effect of parent-to-child aggression on child adiposity, as parental IPV is typically associated with parent-to-child aggression. The reverse is also possible.

\section{Potential dietary mechanisms linking child adiposity to family hostility}

In the RFM, risky health behaviours are posited to be a common proximal factor in multifactor cascades linking risky family social environments to health problems. We focus here on risky health behaviours that affect energy balance, particularly dietary behaviours, given their association with adiposity (Spiegelman \& Flier, 2001). We reason that disturbances of either child and/or parental behaviour around child eating may result from parent-to-child and interparental hostility. Per theoretical perspectives that emphasise the disruption of parental behaviour, the stress of family conflict may compromise parental monitoring and healthy eating routines (Francis, Hofer, \& Birch, 2001) and may cause parents to model maladaptive stress/emotional eating behaviour that their children immitate (Snoek, Engels, Janssens, \& van Strien, 2007). Parents may also offer comfort foods as an emotion regulatory behaviour and/or apologetic compensation for conflict (Coccia, Darling, Rehm, Cui, \& Sathe, 2012). Per perspectives that emphasise the emotional and biological impact of family conflict on the child, family hostility may also result in children's stress eating and preferences for 'comfort foods' (Dallman, Pecoraro, \& la Fleur, 2005). For example, after being berated or hit by a parent or witnessing a fight between parents, a child may eat sweets to down-regulate the associated negative emotion and neuroendocrine response that stimulates a drive toward such foods. The experience of stress is linked to children's and adolescents' emotional eating and consumption of unhealthy food (Jenkins, Rew, \& Sternglanz, 2005; Nguyen-Rodriguez, Unger, \& Spruijt-Metz, 2009). 
Snacking and sugary drink intake, in particular, have both been the subject of significant empirical and media attention in relation to child obesity (Hartocollis, 2012). As reviewed by Davison et al. (2015), child snacking (including soda consumption) is on the rise in the US, contributing a significant proportion of children's daily caloric intake and constituting a key source of 'empty' calories. Concern over these dietary behaviours is reinforced by the findings of longitudinal research that suggests that unhealthy snacking behaviours and soda intake are associated with increases in child adiposity (Shroff et al., 2014). Environmental stressors such as family hostility may play a bigger role in such 'discretionary eating' (i.e., consumption of foods that are not necessary for a healthy diet, and are often have unfavorable calorie-to-nutrition ratios) than they do for consumption during planned meals.

\section{Hypotheses and exploratory questions}

To better understand the potential effects of hostile family environments on child adiposity, this study simultaneously considered parent-to-child and interparental hostility, attempted to disentangle their unique effects, and evaluated discretionary eating as a mediator between family hostility and child adiposity. We hypothesised that parent-to-child (Hypothesis 1) and parent-to-parent (Hypothesis 2) hostility would each predict children's degree of adiposity. To clarify the unique contribution of these related forms of hostility, we examined the extent to which each was associated with child adiposity over and above the influence of the other (Exploratory Question 1). We further hypothesised that two child discretionary dietary behaviours—-sugary drink consumption and obesogenic snacking—would mediate the associations of child adiposity with parent-to-child (Hypothesis 3 ) and parent-to-parent hostility (Hypothesis 4). Due to reports of gender-specific predictors of obesity (Johannsen, Johannsen, \& Specker, 2012), we examined the interaction of hostility with child gender (Exploratory 
Questions 2 and 3). Finally, we evaluated the relative strength of the indirect effects via sugary drink consumption and obesogenic snacking in girls vs. boys (Exploratory Questions 4 and 5).

\section{Method}

\section{Participants}

Participants were 135 couples (male age: $M=44.25, S D=4.93$; female age: $M=42.81$, $S D=4.59)$ and their 6- to 14 -year-old children ( $53 \%$ male; age: $M=10.01 ; S D=1.59)$, residing in exurban New York City. Child gender, coded $1=$ male and $2=$ female, was not significantly associated with child age (Spearman's $\rho=.03, p=.759$ ) or adiposity, as operationalised below, $(\rho=-.06, p=.530)$. Almost all of the couples were married $(99 \%)$, and the median family income was comparable to that of the participants' high-cost-of-living county of residence (\$100,000 [IQR: $\$ 75,000$ to $\$ 147,000]$; county median $=\$ 93,164$ per U.S. Census Bureau [2010]). The mothers and fathers respectively self-identified as White (96\%, 94\%), Black (4\%, $3 \%)$, Asian $(1 \%, 1 \%)$, and multiracial $(0 \%, 2 \%) ; 5 \%$ and $2 \%$ were Latino of any race. The children were 94\% White, 3\% Black, 3\% multiracial, and 1\% Asian; 6\% were Latino of any race. Mean parental BMI was $28.83(S D=6.15)$. Obesity was not an inclusion criterion as our aim was to study the natural range of adiposity in a community sample.

The families were participants in a prior study $(N=399$; Study 2 of Lorber, Xu, Slep, Bulling, \& O'Leary, 2014b), who were originally recruited via telephone using random digit dialing, with an oversample of high-minority areas provided by a sampling firm. Parents eligible for participation must have been English speaking/reading and married or cohabitating for at least one year. At least one parent must have been a biological parent of a 4 - to 8 -year-old child living at home; one child was randomly selected by research staff for the study if there were multiple qualifying children. All families from the original study were invited by mail and 
telephone to participate in the present study. The 135 families who participated did not significantly differ from the 264 families who did not (response rate $=33.83 \%$ ) when compared on 23 demographic (e.g., age, ethnicity, income) and family functioning (e.g., couple conflict behaviour, parental discipline) measures that were available in both waves of data collection (details published in Lorber et al., 2014a).

\section{Procedure}

Families participated in a 2.5 -hour office visit $(n=117)$; those who could or would not travel to the office participated in an abbreviated questionnaire protocol via the Internet $(n=18)$; adiposity and couple observation data were not collected for these families. Each adult partner and child consented or assented to the study. All study methods were approved and overseen by the Institutional Review Board at New York University.

At the office assessment, the parents and children completed paper-and-pencil and computerised questionnaires in separate rooms to ensure anonymity. Child questionnaires are not the focus of the present investigation. Each couple was also observed in two conflict interactions, described below. Finally, children's height, weight, and waist and hip circumferences were measured. Additional procedures were completed but are not the focus of this study. Couples were paid $\$ 150$ for their participation and their children selected a $\$ 10$ gift card to a local restaurant or retailer.

\section{Measures}

Child adiposity. Research staff weighed and measured the study children. Child adiposity was operationalised as a composite of each child's BMI score, adjusted for gender and age (zBMI), as well as waist-hip ratio (WHR), a measure of central adiposity. zBMI was calculated against World Health Organisation (WHO) normative data using the WHO's syntax (World 
Health Organisation, 2011). Waist-hip ratio was calculated as the circumference at the child's natural waist divided by the circumference at the widest spot of her/his hips. Each measure was standardised and then averaged to form the obesity composite score used for further analyses. zBMI and WHR are valuable but imperfect measures of adiposity (Ellis, 2001; Taylor, Jones, Williams, \& Goulding, 2000). Although biomedical researchers typically analyse such measures separately, Ledoux and colleagues (2011) argued that combining measures increases the reliability of the measurement of adiposity, similar to how multi-item questionnaires improve the measurement of psychological constructs. For reference, the zBMIs of $24 \%$ of the children were at or above 1.645 (i.e., upper 5\% of the standard normal distribution), indicating clinical obesity in these children.

Child discretionary diet. Each parent completed study-specific measures of child diet. Two items tapped the frequency of their child's consumption of sugary drinks. Parents were asked how many sugary drinks (i.e., sports drinks, soda, juice, or sugared water) their child has between meals (response scale: $0=0$ times to $5=5$ or more times) and how often their child has sugary drinks before going to bed (response scale: $0=$ Never to $3=$ Always). Standardised zscores were computed for these two items from each of the parents. The four parent-specific items were then averaged to compute the dual-reporter sugary drink consumption variable used for further analyses; Cronbach's $\alpha=.72$.

Each parent also reported on their child's between-meal snacking frequency and snacksof-choice. Their free responses were then coded into five categories of ascending potential to lead to weight gain, based on their calories and nutrient value: $1=$ low calories/high nutrient density (e.g., vegetables), 2 = low calories/low nutrient density (e.g., rice cakes, pretzels), $3=$ medium calories/high nutrient density (e.g., plain yogurt, beans), $4=$ high calories/high nutrient 
density (e.g., animal proteins, peanuts, and tree nuts), and $5=$ high calories/low nutrient density (e.g., fried foods, foods with refined sugars). This scoring reflects the fact that nutrient dense foods at the same calorie level are less likely to lead to weight gain than those that are nonnutrient dense because they are more filling and thus less likely to be followed by the consumption of additional food (see Weigle et al., 2005).

A weight-gain-potential average score across each listed snack was calculated for each parent's reports. These averages were subsequently multiplied by the frequency of snacking, from $0=$ Never to $4=$ Always. A dual-reporter obesogenic snacking composite score that was the subject of the present analyses was then calculated by averaging mothers' and fathers' weight gain potential $\times$ frequency scores. The correlation of mother-to-father child obesogenic snacking scores was .47 .

\section{Hostile parenting.}

Emotional and physical aggression. Parent-to-child emotional and physical aggression were measured via the Family Maltreatment Measure, completed by parents (FM; Foran, Slep, Heyman, \& United States Air Force Family Advocacy Research Program, 2011; Slep, Heyman, \& Snarr, 2011). The FM is an anonymous computerised assessment administered to parents in two modules corresponding to (1) parent-to-child aggression and (2) IPV during the past 12 months. Each module begins with an inventory of aggressive acts; respondents then indicate the frequency (or absence) of each act in the last year. The lists of acts are similar to the Conflict Tactics Scale-Parent Child (CTS-PC) and Revised Conflict Tactics Scales (CTS2) (Straus, Hamby, Boney-McCoy, \& Sugarman, 1996; Straus, Hamby, Finkelhor, Moore, \& Runyan, 1998), although the FM includes additional emotionally and physically aggressive acts that are not present on these measures and isolates specific aggressive acts that were aggregated in those 
measures. The concurrent validity of the FM scales is supported by associations of its scales with several factors in their nomological network (e.g., depression, relationship satisfaction, observed hostility; Slep, Foran, Heyman, \& Snarr, 2011; Lorber et al., 2014a). Internal consistency is not reported for FM subscales per Shortt, Capaldi, Kim, and Owen (2006) and Lorber and Slep (in press) as its items are designed to range from less to more severe forms of aggression, rather than assessing aggression via a combination of related items. They are index scores that do not assume the empirical structure among items (Babbie, 2012).

The Parent Emotional Aggression subscale contains 9 items (e.g., "I did things such as mock my child, put my child down in front of others, spit at my child, etc.”). The frequency of each behaviour is rated from $0=$ Never to $4=$ Once a week to once a day. The mother-to-child and father-to-child emotional aggression scores for analysis were calculated as the mean response to the 9 items for each parent, respectively.

The Parent Physical Aggression subscale contains 18 items (e.g., "I pushed or shoved my child"). Each behaviour is rated as 1/0 (present/absent). The mother-to-child and father-to-child physical aggression scores for analysis were calculated as the mean response to the 18 items for each parent, respectively.

Overreactive discipline. Overreactive discipline was measured by parental report on a short form of the Parenting Scale (PS; Arnold, O'Leary, Wolff, \& Acker, 1993). The PS was originally validated against child behaviour problems and home observations of parenting (Arnold et al., 1993) and more recently via item response theory methods (Lorber et al., 2014b). Using semantic differential-type items, parents rate themselves on a 7-point continuum between two opposing responses to a given child misbehaviour (e.g., 'When my child misbehaves, "I raise my voice or yell" vs. "I speak to my child calmly."”). The short form's 5-item 
Overreactivity subscale reflects parents' angry behaviour in response to child transgressions. The overreactivity score for analysis was the item average; respective $\alpha \mathrm{s}=.76$ and .65 for mothers and fathers.

Latent variable for analysis. A latent hostility composite for each parent was formed by treating the emotional aggression, physical aggression, and overreactivity scores as indicators of an underlying factor (Figure S1, online supplement).

\section{Hostile parent-to-parent behaviour.}

Emotional and physical IPV. Parents completed the Partner Emotional and Physical IPV subscales of the FM, described above. The items were rated on a 6-point frequency-based scale that ranged from $0=$ Never to $5=$ More than 10 times $)$. Alpha is not reported, following the logic presented for the FM parent-to-child aggression index scores. The Partner Emotional IPV subscale's nine items pertain to victimisation by the partner (e.g., "My partner put me down or humiliated me"). Thus, men's perpetration of emotional IPV is derived from women's reports of victimisation, and vice versa. The partner emotional IPV score for analysis was an item average.

The Partner Physical IPV subscale consists of 28 items. The respondent is asked to separately rate the frequency of her/his perpetration of (e.g., "I punched or hit my partner") and victimisation by (e.g., "My partner punched or hit me”) 14 physically aggressive acts. Two intermediate physical IPV scores were calculated for each respondent: the item average of her/his self-reported physical IPV perpetration and victimisation. The maximum of each person's intermediate perpetration (self-report) and victimisation (partner-report) scores was taken as his/her final IPV score. Accordingly, a person's physical IPV score reflected the maximum of how aggressive both $\mathrm{s} / \mathrm{he}$ and his/her partner reported that $\mathrm{s} / \mathrm{he}$ was.

Observed hostility. Couples identified areas of conflict in their relationships using a 
questionnaire that listed common conflictual topics; write-ins were also allowed. Each person privately rated each topic for (a) importance (6-point scale) and (b) whether she/he had raised this issue with his/her partner in the last year (yes/no). For each participant, research staff identified the topic with the highest importance rating that had been discussed in the past year, selecting randomly among ties if necessary. Couples then engaged in two 7-minute interactions, discussing the top-rated conflicts (one female- and one male-identified; the order was counterbalanced), as they might at home.

Hostility (e.g., criticism; rejection) observed during the interactions was rated using the Rapid Marital Interaction Coding System (RMICS; Heyman, 2004), which has established discriminative, convergent, predictive, and construct validity in over 20 studies (Heyman, 2004 for a review). Coders were blind to the study hypotheses. A randomly selected $25 \%$ of the interactions were also coded by a master rater. Interrater agreement was good $(95 \% ; \kappa=.61)$. Hostility scores, the percentage of each person's behaviours scored with the hostility code, were averaged across the two interactions to form the observed hostility variable for analysis.

Latent variable for analysis. A latent hostility composite was formed for each parent with emotional and physical IPV, as well as observed hostility, as indicators of an underlying factor (Figure S1, online supplement).

\section{Analytic strategy}

The hypotheses were evaluated in structural equation (SEM) models with Mplus version 7 software (Muthén \& Muthén, 1998-2012). The rate of missing data was $7.8 \%$. With the exception of the descriptive data presented in Table 1, we used robust full information maximum likelihood estimation (FIML) to include cases with missing data, avoiding the biases of listwise deletion (Schafer \& Graham, 2002), and with model fit indices and parameter $S E$ s adjusted for 
skewness.

[Table 1 near here]

Each model is named by its corresponding hypothesis $(\mathrm{H})$ or exploratory $(\mathrm{E})$ test and by the gender of the parent ( $\mathrm{M}$ for mothers and $\mathrm{F}$ for fathers). To test Hypotheses 1 and 2, we modeled child adiposity as an outcome of the latent parent-to-child and parent-to-parent hostility factors, each studied separately. We first examined mother-to-child and mother-to-father hostility (Models $\mathrm{H} 1_{\mathrm{M}}$ and $\mathrm{H}_{\mathrm{M}}$ ), as well as father-to-child and father-mother hostility (Models $\mathrm{H} 1_{\mathrm{F}}$ and $\mathrm{H} 2 \mathrm{~F}$ ), to examine the bivariate association of each hostility factor with adiposity. For each significant predictor of adiposity, we evaluated indirect effects via two dietary behaviours: obesogenic snacking and sugary drink consumption (Models H3.1 $\mathrm{M}$ and H3.2M).

We next disentangled the contributions of parent-to-child and parent-to-parent adiposity. We tested the unique association of adiposity with mother-to-child and mother-to-father hostility to examine Exploratory Question 1 (Model E1 $1_{\mathrm{M}}$ ). No tests were required to disentangle the unique contributions of father-to-child and father-mother hostility, as neither factor was significantly associated with adiposity.

To test Exploratory Questions 2 and 3, we examined the moderation by gender of the associations of adiposity with parent-to-child (Models E2 ${ }_{\mathrm{M}}$ and $\mathrm{E} 2 \mathrm{~F}$ ) and parent-to-parent (Models $\mathrm{E}_{\mathrm{M}}$ and $\mathrm{E} 3_{\mathrm{F}}$ ) hostility. Finally, for cases in which hostility-gender interactions were significant, we further evaluated the relative strength of the indirect effects via sugary drinks (Models E4.1 $1_{\mathrm{M}}$ and E5.1 $1_{\mathrm{M}}$ ) and obesogenic snacking (Models E4.2 $\mathrm{M}$ and E5.2M) in girls vs. boys; Exploratory Questions 4 and 5 (i.e., moderated mediation).

\section{Results}

Descriptive statistics for and associations among manifest study variables are presented 
in Table 1. Model fit (Table S1, online supplement) was generally adequate according to conventions outlined by Kline (2010): comparative fit index (CFI) and Tucker-Lewis Index $(\mathrm{TLI}) \geq .90$ and a root mean square error approximation (RMSEA) $\leq .08$. These thresholds are heuristic; fixed cutoffs are often arbitrary and RMSEA in particular is difficult to interpret in low $d f$ models (e.g., the $2 d f$ models we test here; Kenny, Kaniskan, \& McCoach, 2015).

\section{Child Adiposity in Relation to Maternal and Paternal Hostility}

Maternal main effects. To test Hypothesis 1, a latent mother-to-child hostility variable was formed by (a) isolating the shared variance in three indicators: mother-to-child emotional aggression, physical aggression, and overreactivity, and (b) regressing child adiposity on the latent mother-to-child hostility composite (Model $\mathrm{H} 1_{\mathrm{M}}$, Table 2, Figure S2). The factor loadings were significant $(p \mathrm{~s}<.001)$, and child adiposity was significantly associated with mother-tochild hostility $\left(R^{2}=.07\right)$, consistent with Hypothesis 1 . We note, however, that emotional aggression was the only variable from the mother-to-child hostility composite to have a significant bivariate association with adiposity, per the Table 1 results.

[Table 2 near here]

To test Hypothesis 2, a latent mother-to-father hostility variable was formed by (a) isolating the shared variance in three indicators: mother-to-father emotional IPV, physical IPV, and observed hostility, and (b) regressing child adiposity on the latent mother-to-father hostility composite (Model H2 $2_{\mathrm{M}}$, Table 2, Figure S2). The factor loadings were significant ( $p \mathrm{~s}<.001$ ), but child adiposity was not significantly associated with mother-to-father hostility $\left(R^{2}=.01\right)$; Hypothesis 2 was not supported.

Disentangling maternal effects. To test Exploratory Question 1, child adiposity was simultaneously regressed on the aforementioned mother-to-child and mother-to-father latent 
hostility factors (Model E1 1 , Table 2, Figure S2). Mother-to-child and mother-to-father hostility were allowed to covary. Controlling for mother-to-father hostility, mother-to-child hostility was uniquely associated with child adiposity to a similar extent as found in $\operatorname{Model} \mathrm{H} 1_{\mathrm{M}}\left(R^{2}=.06\right)$, although the association was only marginally significant $(p<.10)$ due to a larger $S E$ in $\mathrm{E} 1_{\mathrm{M}}$ than in $\mathrm{H} 1_{\mathrm{M}}$. The unique association of mother-to-father hostility and child adiposity, controlling for mother-to-child hostility, was nonsignificant.

Paternal main effects. Models $\mathrm{H} 1_{\mathrm{F}}$ and $\mathrm{H} 2_{\mathrm{F}}$ were respectively parallel to Models $\mathrm{H} 1_{\mathrm{M}}$ and $\mathrm{H} 2 \mathrm{M}$, but father-to-child and father-mother hostility variables were substituted in place of mother-to-child and mother-to-father hostility (Table 2, Figure S3). The factor loadings were significant in each case $(p \mathrm{~s}<.001)$, however child adiposity was not significantly associated with father-to-child $\left(R^{2}=.02\right)$ or father-mother $\left(R^{2}=.01\right)$ hostility. Thus, Hypotheses 1 and 2 were not supported where fathers' behaviour was concerned.

Mediation of maternal hostility effects via child diet. Indirect effects were evaluated in the context of models in which a dietary mediator variable (e.g., obesogenic snacking) was regressed on a hostility predictor variable (e.g., mother-to-child hostility; $\alpha$ path) and adiposity was simultaneously regressed on the dietary mediator ( $\beta$ path) and the predictor. These effects were evaluated via the product of $\alpha \beta$ method with bias-corrected bootstrapped asymmetrical CIs and 10,000 draws (MacKinnon et al., 2002). The effect size of the indirect effects was expressed as the ratio of the $\alpha \beta$ product to the maximum possible mediation effect - the $\mathrm{K}^{2}$ measure, which can be interpreted similarly to $R^{2}$ (Preacher \& Kelley, 2011). The predictors were latent variables structured as in the main effects tests of $\mathrm{H} 1$ and $\mathrm{H} 2$.

The mother-to-child hostility $\rightarrow$ sugary-drinks $\rightarrow$ adiposity indirect effect (Model H3.1 M; Figure 1) fell just short of significance, as the lower limit of its confidence interval sat just below 
zero, $\alpha \beta=0.04$ (95\% CI: $-0.001,0.143), \mathrm{K}^{2}=0.04$. The same was true of the $\alpha(0.20 ; 95 \% \mathrm{CI}$ : $0.002,0.413)$ and $\beta(0.20 ; 95 \% \mathrm{CI}:-0.019,0.411)$ paths. The mother-to-child hostility $\rightarrow$ obesogenic snacking $\rightarrow$ adiposity indirect effect (Model H3.2M) was nonsignificant, $\alpha \beta$ $=-0.01(95 \%$ CI: $-0.09,0.05), \mathrm{K}^{2}=0.01$; although the $\alpha$ path was significant $(0.31 ; 95 \% \mathrm{CI}$ : $0.10,0.51)$, the $\beta$ path was not $(-0.02 ; 95 \%$ CI: $-0.21,0.16)$. In sum, Hypothesis 3 was not supported with regard to sugary drinks or obesogenic snacking.

Because Hypotheses 1 and 2 were not supported where fathers' behaviour was concerned, as reported above, no follow-up tests to explore mediation by dietary factors were appropriate (i.e., Hypotheses 3 and 4 were not supported).

[Figure 1 near here]

Associations of Child Adiposity with Mothers' Hostility as Moderated by Child Gender

Multigroup analyses were used to evaluate Hostility $\times$ Child Gender interactions. Pairs of models were fit in which the hostility-adiposity association was equated in boys and girls (constrained model; C) or allowed to freely vary (unconstrained model; U). All variables were standardised to avoid conflating differences in association strength between genders with differences in variances. Comparative model fit was evaluated via scaled $\chi^{2}$ difference tests (Satorra \& Bentler, 2001). These models were examined for each adiposity-hostility association. The predictors were latent variables structured as in the main effects tests of $\mathrm{H} 1$ and $\mathrm{H} 2$. Measurement model parameters were equated across genders.

Mother-to-child hostility. The association of mother-to-child hostility and child adiposity was significantly moderated by child gender (Figure 2). Model fit was acceptable for the constrained (Model E2 $2_{\mathrm{M}, \mathrm{C}}$ ) and unconstrained models (Model E2 $\mathrm{M}_{\mathrm{M}, \mathrm{U}}$ ) but was significantly worse for the constrained model, $\chi^{2}$ change $(1)=8.80, p=.003$. For boys, the association of adiposity with 
mother-to-child hostility was significant $(\beta=0.46, S E=0.15, p=.001 ; 95 \% \mathrm{CI}: 0.18,0.75)$, whereas the parallel association was nonsignificant for girls $(\beta=0.05, S E=0.14, p=.708 ; 95 \%$ CI: $-0.23,0.33)$.

Mother-to-father hostility. The association of mother-to-father hostility and child adiposity was also significantly moderated by child gender. Model fit was again acceptable for the constrained (Model E3 ${ }_{\mathrm{M}, \mathrm{C}}$ ) and unconstrained models (Model E3 $3_{\mathrm{M}, \mathrm{U}}$ ) but was significantly worse for the constrained model, $\chi^{2}$ change $(1)=5.45, p=.020$. For boys, the association of adiposity with mother-to-father hostility was marginally significant and positive $(\beta=0.22, S E=$ $0.13, p=.080 ; 95 \% \mathrm{CI}:-0.03,0.47)$, whereas the parallel association was nonsignificant and negative for girls $(\beta=-0.16, S E=0.14, p=.255 ; 95 \% \mathrm{CI}:-0.43,0.12)$.

[Figure 2 near here]

Mediation by diet. Given the significant Hostility $\times$ Child Gender interactions reported above, the moderation of the mother-to-child hostility $\rightarrow$ diet $\rightarrow$ adiposity indirect effects by child gender was evaluated (i.e., moderated mediation). To accomplish this, the indirect effects were reevaluated via multigroup analysis.

Mother-to-child hostility. Sugary drink consumption was regressed on mother-to-child hostility $(\alpha)$ and adiposity was simultaneously regressed on sugary drink consumption $(\beta)$ and mother-to-child hostility. All variables were standardised. In Model E4.1 $1_{\mathrm{M}, \mathrm{C}}$, the $\alpha$ and $\beta$ paths were equated for boys and girls; in Model E4.1 $\mathrm{M,U}$ (unconstrained), these paths were freely estimated. Each model fit the data well and the constrained model did not exhibit worse fit, $\chi^{2}$ change $(2)=3.38, p=.184$. A parallel pair of multigroup models were estimated, substituting obesogenic snacking in place of sugary drink consumption (Models E4.2 ${ }_{\mathrm{M}, \mathrm{C}}$ and $\mathrm{E} 4.2_{\mathrm{M}, \mathrm{U}}$ ). As above, each model fit the data well and the constrained model did not exhibit worse fit, $\chi^{2}$ change 
$(2)=0.47, p=.790$.

Mother-to-father hostility. A second set of moderated mediation models was estimated following the above method, this time with mother-to-father hostility as the predictor. Neither indirect effect, via sugary drinks consumption [Models E5.1 $1_{\mathrm{M}, \mathrm{C}}$ vs. E5.1M,U; $\chi^{2}$ change $(2)=1.56, p$ $=.458$ ] or obesogenic snacking [Models E5.2 $2_{\mathrm{M}, \mathrm{C}}$ vs. E5.2 $2_{\mathrm{M}, \mathrm{U}} ; \chi^{2}$ change $(2)=1.04, p=.595$ ], significantly differed for boys and girls.

\section{Associations of Child Adiposity with Fathers' Hostility as Moderated by Child Gender}

There was no evidence that child gender moderated the associations of child adiposity with father-to-child or father-mother hostility. These interactions were evaluated in a parallel set of analyses to those of mothers' hostility. Each model fit the data well (Table S2) and the unconstrained models, compared to the constrained models, did not exhibit better fit in the case of father-to-child hostility [Models E2 $2_{\mathrm{F}, \mathrm{C}} \mathrm{vs} . \mathrm{E} 2 \mathrm{~F}, \mathrm{U} ; \chi^{2}$ change $(1)=0.34, p=.563$ ] or father-mother hostility [Models $\mathrm{E} 3_{\mathrm{F}, \mathrm{C}} \mathrm{vs} . \mathrm{E} 3_{\mathrm{F}, \mathrm{U}} ; \chi^{2}$ change $(1)=2.37, p=.124$ ].

\section{Discussion}

Children whose mothers reported greater child-directed hostility exhibited higher levels of adiposity. This association was concentrated in boys and was not the result of confounding between parent-to-child and interparental hostility. Mother-to-father hostility was not significantly associated with child adiposity in the full sample, but showed a similar pattern of moderation in that it was differentially associated with boys' and girls' adiposity. Yet the association of adiposity and mother-to-father hostility was not statistically significant for either gender.

Mother-to-child emotional aggression was the only significant directly measured predictor of child adiposity among the maternal hostility indicators. Parenting practices such as 
humiliation, threats of abandonment, and confinement — more than hitting or 'garden variety' angry parenting — may be particularly linked to child adiposity. Given our findings, if motherto-child hostility plays a causal role in boys' adiposity, it may be due to persistent long-term exposure to levels of hostility that fall below the thresholds for clinically significant abuse. Hostile parenting appears to be remarkably stable (O'Leary, Slep, \& Reid, 1999). Yet our finding contrasts with those reported by Gooding et al. (2015) and Whitaker et al. (2007), where emotional abuse was not significantly associated with child or adolescent BMI. Given these contradictory findings, future studies, and perhaps a meta-analytic review, will be necessary to substantiate the association.

We failed to find support for the mediating role played by children's consumption of sugary drinks and generalised obesogenic snacking (i.e., discretionary eating), although obesogenic snacking was greater among children whose mothers were more hostile toward them. Moreover, approximately $4 \%$ of the total association of mother-to-child hostility and child adiposity was explained by sugary drink intake. The indirect effect was statistically nonsignificant. Given the indirect effect's small size, the present sample may have been underpowered to detect it. One might further expect that this possible mediated effect in the full sample would be stronger in boys, given that mother-to-child hostility and adiposity were more strongly associated in boys than in girls. Yet there was no evidence that this was the case. Accordingly, if mother-to-child hostility impacts boys' and girls' adiposity differently, the mechanism responsible for this difference is likely something other than sugary drink intake. Future research could investigate other possibilities, including increased sedentary behaviour and emotional and neuroendocrine disturbances that are associated with environmental stressors and child adiposity (Davies, Sturge-Apple, Cicchetti, Manning, \& Zale, 2009; Schmitz et al., 2002). 
We failed to find support for the hypothesised associations of girls' adiposity with any measure of family hostility. The inconsistency may reflect a three-way interaction, where adiposity and hostile family environments are associated at different ages to a different extent for boys and girls. For example, in Boynton-Jarrett et al. (2010), mothers' physical IPV victimisation predicted preschool girls' obesity. As children aged into adolescence, mothers' victimisation was more likely to predict boys' obesity (Jun et al., 2012). Our participants fell between the age groups of Boynton-Jarrett et al. (2010) and Jun et al. (2012).

We also failed to find a link between child adiposity and either father-mother or father-tochild hostility. It is possible that maternal influence may be greater given children's greater exposure to mothers' behaviour, as mothers contribute disproportionately to childcare (Parke, 1995). It may also be that mothers' hostility toward fathers is frequently childcare-related and more associated with child outcomes than is fathers' hostility, which may be less child-specific.

\section{Implications for Intervention}

Researchers have long hypothesised the role of hostile family environments in children's compromised physical health (Repetti, Robles, \& Reynolds, 2011). Yet the field has only recently begun to leverage these processes to improve children's physical health. Brotman and colleagues' (2012) recent study is particularly illuminating. In two long-term randomised trials, parent-child dyads who received a family intervention at age 4 had lower BMIs in preadolescence. What is particularly striking about this study is that the intervention had nothing to do with child nutrition, activity, or weight; it was designed to prevent behaviour problems (e.g., aggression) among high-risk children, primarily by changing parenting practices (e.g., discipline style). This work suggests that changing family environmental factors that have no obvious or direct link to child adiposity can yield unexpected and long-term physical health benefits. 
Ultimately, a multidisciplinary approach to prevention may prove to be the most powerful. Limitations

Our cross-sectional design did not permit for the temporal precedence of the putative causes (hostility) to the mediators (dietary behaviours) and outcome (child adiposity). Alternative directions of causality are possible. For example, mothers' hostility toward their heavier sons may have been in part a reaction to their sons' adiposity. Obese individuals have an elevated risk of hostile interpersonal behaviour directed at them (Puhl \& Brownell, 2001). Further studies with designs that preserve the temporal precedence of cause and effect will be necessary to clarify causality in the relations we documented.

Our failure to find support for links between family hostility and girls' adiposity may be a result of insufficient power. As discussed above, we speculate that a three-way interaction (i.e., gender of parent, gender of child, and age of child) may be at work. Our sample size did not provide enough power to adequately investigate this possibility.

The negative findings related to dietary mediation of the maternal hostility-child adiposity association, in addition to being a function of low statistical power, may have reflected measurement error in our assessment of child diet. Diary measures of diet (e.g., Christian et al., 2014) are the present state-of-the-art and are thought to provide more accurate assessments than do retrospective measures such as those used in this study. Our dietary assessment might have been further improved by the inclusion of direct measures of stress eating, with such measures reflecting the tendency to eat differently when experiencing stress (Nguyen-Rodriguez et al., 2009).

Additionally, the present sample largely comprised White middle- to upper-middle-class, two-parent families. It was necessary to study two-parent families to disentangle the influences 
of interparental and parent-to-child hostility. Furthermore, the sample was reasonably representative of the exurban area from which it was drawn, thus enhancing the generalisability of the present findings to such populations. Non-Hispanic whites are almost 2/3 of the American population, and roughly $3 / 4$ of non-Hispanic white children live in two-parent families (U.S.

Census Bureau, 2007-2011). Yet there is no guarantee that our findings will generalise to singleparent, racial/ethnic minority, and/or more disadvantaged populations families; these are questions that can only be answered with additional research.

\section{Conclusion}

This study provides evidence that mothers' hostility toward their sons is associated with boys' adiposity. Although mother-to-son hostility was also associated with child obesogenic snacking, neither obesogenic snacking or sugary drink consumption explained the association of mother-to-son hostility and boys' adiposity. Ours is the first study to take a family-level approach to understanding the relation between hostility and child adiposity by studying the hostility of both mothers and fathers toward one another and their children. This feature allowed us to disentangle the relative contributions of each of these behaviours to child adiposity. Our findings suggest that mothers' hostility toward their children may be a promising target for the prevention of child obesity. 


\section{References}

Anderson, S. E., Gooze, R. A., Lemeshow, S., \& Whitaker, R. C. (2011). Quality of early maternal-child relationship and risk of adolescent obesity. Pediatrics, 129, 132-140. doi:10.1542/peds.2011-0972

Arnold, D. S., O'Leary, S. G., Wolff, L. S., \& Acker, M. M. (1993). The Parenting Scale: A measure of dysfunctional parenting in discipline situations. Psychological Assessment, 5, 137.

Babbie, E. R. (2012). The Practice of social research. Belmont, CA: Wadsworth Publishing.

Birch, L. L. (2006). Child feeding practices and the etiology of obesity. Obesity, 14, 343-344. doi:10.1038/oby.2006.45

Boynton-Jarrett, R., Fargnoli, J., Suglia, S. F., Zuckerman, B., \& Wright, R. J. (2010). Association between maternal intimate partner violence and incident obesity in preschool-aged children results from the Fragile Families and Child Well-Being Study. Archives of Pediatrics \& Adolescent Medicine, 164, 540-546.

Brotman, L. M., Dawson-McClure, S., Huang, K. Y., Theise, R., Kamboukos, D., Wang, J., .. . Ogedegbe, G. (2012). Early childhood family intervention and long-term obesity prevention among high-risk minority youth. Pediatrics, 129, e621-628.

Burke, N. J., Hellman, J. L., Scott, B. G., Weems, C. F., \& Carrion, V. G. (2011). The impact of adverse childhood experiences on an urban pediatric population. Child Abuse \& Neglect, $35,408-413$.

Christian, M. S., Evans, C. E., Nykjaer, C., Hancock, N., \& Cade, J. E. (2014). Measuring diet in primary school children aged 8-11 years: validation of the Child and Diet Evaluation 
Tool (CADET) with an emphasis on fruit and vegetable intake. European Journal of Clinical Nutrition, 69, 234-241. doi:10.1038/ejcn.2014.160

Coccia, C., Darling, C. A., Rehm, M., Cui, M., \& Sathe, S. K. (2012). Adolescent health, stress and life satisfaction: The paradox of indulgent parenting. Stress and Health, 28, 211-221. doi: $10.1002 /$ smi. 1426

Dallman, M. F., Pecoraro, N. C., \& la Fleur, S. E. (2005). Chronic stress and comfort foods: Self-medication and abdominal obesity. Brain, Behaviour, and Immunity, 19, 275-280.

Danese, A., Caspi, A., Williams, B., Ambler, A., Sugden, K., Mika, J., . . Arsenault, L. (2011). Biological embedding of stress through inflammation processes in childhood. Molecular Psychology, 16, 244-246. doi: 10.1038/mp.2010.5

Daniels, S. R. (2009). Complications of obesity in children and adolescents. International Journal of Obesity, 33, S60-S65. doi: 10.1038/Ijo.2009.20

Davies, P. T., Sturge-Apple, M. L., Cicchetti, D., Manning, L. G., \& Zale, E. (2009). Children's patterns of emotional reactivity to conflict as explanatory mechanisms in links between interpartner aggression and child physiological functioning. Journal of Child Psychology and Psychiatry, 50, 1384-1391. doi: 10.1111/j.1469-7610.2009.02154.x

Davison, K. K., Blake, C. E., Blaine, R. E., Younginer, N. A., Orloski, A., Hamtil, H. A., ... \& Fisher, J. O. (2015). Parenting around child snacking: development of a theoreticallyguided, empirically informed conceptual model. International Journal of Behavioural Nutrition and Physical Activity, 12, 1-11. doi:10.1186/s12966-015-0268-3

Ellis, K. J. (2001). Selected body composition methods can be used in field studies. The Journal of Nutrition, 131, 1589S-1595S. 
Falkner, N. H., Neumark-Sztainer, D., Story, M., Jeffery, R. W., Beuhring, T., \& Resnick, M. D. (2001). Social, educational, and psychological correlates of weight status in adolescents. Obesity Research, 9, 32-42. doi: 10.1038/Oby.2001.5

Fiese, B. H., \& Bost, K. K. (2016). Family ecologies and child risk for obesity: Focus on regulatory processes. Family Relations, 65, 94-107. doi:10.1111/fare.12170

Foran, H. M., Slep, A. M. S., Heyman, R. E., \& United States Air Force Family Advocacy Research Program. (2011). Prevalences of intimate partner violence in a representative U.S. Air Force sample. Journal of Consulting and Clinical Psychology, 79, 391-397. doi: 10.1037/A0022962

Francis, L. A., Hofer, S. M., \& Birch, L. L. (2001). Predictors of maternal child-feeding style: Maternal and child characteristics. Appetite, 37, 231-243. doi: 10.1006/appe.2001.0427

Gooding, H. C., Milliren, C., Austin, S. B., Sheridan, M. A., \& McLaughlin, K. A. (2015). Exposure to violence in childhood is associated with higher body mass index in adolescence. Child Abuse and Neglect, 50, 151-158. doi: 10.1016/j.chiabu.2015.08.005

Hartocollis, A. (2012, May 31). To gulp or to sip? Debating a crackdown on big sugary drinks. New York Times. Retrieved from http://www.nytimes.com

Heyman, R. E. (2004). Rapid Marital Interaction Coding System (RMICS). In P. K. Kerig \& D. H. Baucom (Eds.), Couple observational coding systems (pp. 67-94). Mahwah, NJ: Lawrence Erlbaum Associates.

Hussey, J. M., Chang, J. J., \& Kotch, J. B. (2006). Child maltreatment in the United States: Prevalence, risk factors, and adolescent health consequences. Pediatrics, 118, 933-942. doi: $10.1542 /$ peds.2005-2452 
Jenkins, S. K., Rew, L., \& Sternglanz, R. W. (2005). Eating behaviours among school-age children associated with perceptions of stress. Issues in Comprehensive Pediatric Nursing, 28, 175-191. doi: 10.1080/01460860500227580

Johannsen, D. L., Johannsen, N. M., \& Specker, B. L. (2012). Influence of parents' eating behaviours and child feeding practices on children's weight status. Obesity, 14, 431-439. doi: $10.1038 /$ oby.2006.57

Jun, H. J., Corliss, H. L., Boynton-Jarrett, R., Spiegelman, D., Austin, S. B., \& Wright, R. J. (2012). Growing up in a domestic violence environment: Relationship with developmental trajectories of body mass index during adolescence into young adulthood. Journal of Epidemiology and Community Health, 66, 629-635. doi:

10.1136/Jech.2010.110932

Kenny, D. A., Kaniskan, B., \& McCoach, D. B. (2015). The performance of RMSEA in models with small degrees of freedom. Sociological Methods and Research, 44, 486-507. doi: $10.1177 / 0049124114543236$

Kline, R. B. (2010). Principles and practice of structural equation modeling. New York, NY: Guilford.

Ledoux, T., Watson, K., Baranowski, J., Tepper, B. J., \& Baranowski, T. (2011). Overeating styles and adiposity among multiethnic youth. Appetite, 56, 71-77. doi: 10.1016/j.appet.2010.11.145

Li, Y. F., Dai, Q., Jackson, J. C., \& Zhang, J. (2008). Overweight is associated with decreased cognitive functioning among school-age children and adolescents. Obesity, 16, 18091815. doi: $10.1038 /$ Oby.2008.296 
Lorber, M. F., \& O’Leary, K. D. (2012). Stability, change, and informant variance in newlyweds' physical aggression: Individual and dyadic processes. Aggressive Behavior, 38, 1-15. doi: 10.1002/ab.20414

Lorber, M. F., \& Slep, A. M. S. (in press). The reliability paradox of the Parent-Child Conflict Tactics Corporal Punishment subscale. Journal of Family Psychology. doi: $10.1037 /$ fam0000307

Lorber, M. F., Slep, A. M. S., Heyman, R. E., Xu, S., Dasanayake, A. P., \& Wolff, M. S. (2014a). Noxious family environments are associated with adult and childhood caries. Journal of the American Dental Association, 145, 924-930. doi:10.14219/jada.2014.55

Lorber, M. F., Xu, S., Slep, A. M. S., Bulling, L. J., \& O'Leary, S. G. (2014b). A new look at the psychometrics of the Parenting Scale through the lens of item response theory. Journal of Clinical Child and Adolescent Psychology, 43, 613-626. doi: $10.1080 / 15374416.2014 .900717$

Lumeng, J. C., Forrest, P., Appugliese, D. P., Kaciroti, N., Corwyn, R. F., \& Bradley, R. H. (2010). Weight status as a predictor of being bullied in third through sixth grades. Pediatrics, 125, E1301-E1307. doi: 10.1542/Peds.2009-0774

MacKinnon, D. P., Lockwood, C. M., Hoffman, J. M., West, S. G., \& Sheets, V. (2002). A comparison of methods to test mediation and other intervening variable effects. Psychological Methods, 7, 83-104. doi: 10.1037/1082-989X.7.1.83

Maguire-Jack, K., Gromoske, A. N., \& Berger, L. M. (2012). Spanking and child development during the first 5 years of life. Child Development, 83, 1960-1977. http://dx.doi.org/10.1111/j.1467-8624.2012.01820.x 
Midei, A. J., \& Matthews, K. A. (2011). Interpersonal violence in childhood as a risk factor for obesity: a systematic review of the literature and proposed pathways. Obesity Reviews, 12, e159-e172. doi:10.1111/j.1467-789X.2010.00823.x.

Muthén, L. K., \& Muthén, B. O. (1998-2012). Mplus user's guide. Seventh edition. Los Angeles, California: Muthén \& Muthén.

Nguyen-Rodriguez, S. T., Unger, J. B., \& Spruijt-Metz, D. (2009). Psychological determinants of emotional eating in adolescence. Eating Disorders, 17, 211-224. doi:10.1080/10640260902848543

Ogden, C. L., Carroll, M. D., Kit, B. K., \& Flegal, K. M. (2012). Prevalence of obesity and trends in body mass index among US children and adolescents, 1999-2010. Journal of the American Medical Association, 307, 483-490. doi: 10.1001/Jama.2012.40

O'Leary, S. G., Slep, A. M. S., \& Reid, J. (1999). A longitudinal study of mothers' overreactive discipline and toddlers' externalizing behaviour. Journal of Abnormal Child Psychology, 27, 331-341. doi: 10.1023/A:1021919716586

Parke, R. D. (1995). Fathers and families. In M. H. Bornstein (Ed.), Handbook of parenting: Volume 3. Status and social conditions of parenting (pp. 27-63). Mahwah, NJ: Erlbaum.

Preacher, K. J., \& Kelley, K. (2011). Effect size measures for mediation models: quantitative strategies for communicating indirect effects. Psychological Methods, 16, 93 -115. doi:10.1037/a0022658

Puhl, R., \& Brownell, K. D. (2001), Bias, discrimination, and obesity. Obesity Research, 9, 788805. doi:10.1038/oby.2001.108

Repetti, R. L., Robles, T. F., \& Reynolds, B. (2011). Allostatic processes in the family. Development and Psychopathology, 23, 921-938. 
Repetti, R. L., Taylor, S. E., \& Seeman, T. E. (2002). Risky families: family social environments and the mental and physical health of offspring. Psychological Bulletin, 128, 330-366. doi: $10.1037 / / 0033-2909.128 .2 .330$

Rivas, M. A. (2013). The relationship between exposure to intimate partner violence, behaviour problems and weight status in preschool age children in Head Start programs. McNair Scholars Research Journal, 6, 105-124.

Saldanha-Gomes, C., Heude, B., Charles, M. A., de Lauzon-Guillain, B., Botton, J., Carles, S., ... \& Lioret, S. (2016). Prospective associations between energy balance-related behaviors at 2 years of age and subsequent adiposity: the EDEN mother-child cohort. International Journal of Obesity, 41, 38-45. doi:10.1038/ijo.2016.138

Satorra, A., \& Bentler, P. M. (2001). A scaled difference chi-square test statistic for moment structure analysis. Psychometrika, 66, 507-514. doi:10.1007/bf02296192

Schafer, J. L., \& Graham, J. W. (2002). Missing data: Our view of the state of the art. Psychological Methods, 7, 147-177. doi: 10.1037//1082-989x.7.2.147

Schmitz, K. H., Lytle, L. A., Phillips, G. A., Murray, D. M., Birnbaum, A. S., \& Kubik, M. Y. (2002). Psychosocial correlates of physical activity and sedentary leisure habits in young adolescents: the Teens Eating for Energy and Nutrition at School study. Preventive Medicine, 34, 266-278. doi:10.1006/pmed.2001.0982

Schneiderman, J. U., Mennen, F. E., Negriff, S., \& Trickett, P. K. (2012). Overweight and obesity among maltreated young adolescents. Child Abuse and Neglect, 36, 370-378. doi:10.1016/j.chiabu.2012.03.001 
Shin, S. H., \& Miller, D. P. (2012). A longitudinal examination of childhood maltreatment and adolescent obesity: Results from the National Longitudinal Study of Adolescent Health (AddHealth) Study. Child Abuse \& Neglect, 36, 84-94. doi: 10.1016/j.chiabu.2011.08.007

Shortt, J. W., Capaldi, D. M., Kim, H. K., \& Owen, L. D. (2006). Relationship separation for young, at-risk couples: prediction from dyadic aggression. Journal of Family Psychology, 20, 624-631. doi: 10.1037/0893-3200.20.4.624

Shroff, M. R., Perng, W., Baylin, A., Mora-Plazas, M., Marin, C., \& Villamor, E. (2014). Adherence to a snacking dietary pattern and soda intake are related to the development of adiposity: A prospective study in school-age children. Public Health Nutrition, 17, 15071513. doi:10.1017/S136898001300133X

Slep, A. M. S., Heyman, R. E., \& Snarr, J. D. (2011). Child emotional aggression and abuse: Definitions and prevalence. Child Abuse \& Neglect, 35, 783-796. doi: 10.1010/J.Chiabu.2011.07.002

Slep, A. M. S., Foran, H. M., Heyman, R. E., \& Snarr, J. D. (2011). Risk factors for clinically significant intimate partner violence among active-duty members. Journal of Marriage and Family, 73, 486-501. doi: 10.1111/j.1741-3737.2010.00820.x

Slep, A. M. S., \& O'Leary, S. G. (2005). Parent and partner violence in families with young children: Rates, patterns, and connections. Journal of Consulting and Clinical Psychology, 73, 435-444. doi: 10.1037/0022-006x.73.3.435Snoek, H. M., Engels, R. C., Janssens, J. M., \& van Strien, T. (2007). Parental behaviour and adolescents' emotional eating. Appetite, 49, 223-230. doi:10.1016/j.appet.2007.02.004

Spiegelman, B. M., \& Flier, J. S. (2001). Obesity and the regulation of energy balance. Cell, 104, 531-543. doi: 10.1016/S0092-8674(01)00240-9 
Straus, M. A., Hamby, S. L., Boney-McCoy, S., \& Sugarman, D. B. (1996). The revised Conflict Tactics Scales (CTS2): Development and preliminary psychometric data. Journal of Family Issues, 17, 283-316. doi: 10.1177/019251396017003001

Straus, M. A., Hamby, S. L., Finkelhor, D., Moore, D. W., \& Runyan, D. (1998). Identification of child maltreatment with the parent-child Conflict Tactics Scales: Development and psychometric data for a national sample of American parents. Child Abuse \& Neglect, 22, 249-270. doi: 10.1016/S0145-2134(97)00174-9

Taylor, R. W., Jones, I. E., Williams, S. M., \& Goulding, A. (2000). Evaluation of waist circumference, waist-to-hip ratio, and the conicity index as screening tools for high trunk fat mass, as measured by dual-energy x-ray absorptiometry, in children aged 3-19 y. The American Journal of Clinical Nutrition, 72, 490-495.

U.S. Census Bureau. (2007-2011). United States, DP05 ACS demographic and housing estimates [Data]. 2012 American Community Survey 5-Year Estimates. Retrieved from http://factfinder2.census.gov

U.S. Census Bureau. (2010). Suffolk County, New York, DP03. Selected economic characteristics in the United States [Data]. 2010 American Community Survey 1-Year Estimates. Retrieved from http://factfinder2.census.gov 
Weigle, D. S., Breen, P. A., Matthys, C. C., Callahan, H. S., Meeuws, K. E., Burden, V. R., \& Purnell, J. Q. (2005). A high-protein diet induces sustained reductions in appetite, ad libitum caloric intake, and body weight despite compensatory changes in diurnal plasma leptin and ghrelin concentrations. The American Journal of Clinical Nutrition, 82, 41-48. Retrieved from http://ajcn.nutrition.org/

Whitaker, R. C., Phillips, S. M., Orzol, S. M., \& Burdette, H. L. (2007). The association between maltreatment and obesity among preschool children. Child Abuse \& Neglect, 31, $1187-$ 1199. doi: 10.1016/j.chiabu.2007.04.008

World Health Organization. (2011). WHO anthro (version 3.2.2, January 2011) and macros. from http://www.who.int/childgrowth/software/en/ 
Table 1

Descriptive Statistics for and Correlations among Study Measures

\begin{tabular}{|c|c|c|c|c|c|c|c|c|c|c|c|c|c|c|c|c|c|}
\hline & 1 & 2 & 3 & 4 & 5 & 6 & 7 & 8 & 9 & 10 & 11 & 12 & 13 & 14 & 15 & 16 & 17 \\
\hline 1. Child adiposity & - & & & & & & & & & & & & & & & & \\
\hline $\begin{array}{l}\text { 2. Child zBMI } \\
\text { 3. Child waist/hip }\end{array}$ & .87 & - & & & & & & & & & & & & & & & \\
\hline ratio & .83 & .46 & - & & & & & & & & & & & & & & \\
\hline 4. Sugary drinks & .22 & .16 & .21 & - & & & & & & & & & & & & & \\
\hline $\begin{array}{l}\text { 5. Obesogenic } \\
\text { snacks }\end{array}$ & .03 & .04 & .04 & .26 & - & & & & & & & & & & & & \\
\hline 6. M-C emotional & .25 & .24 & .14 & .14 & .16 & - & & & & & & & & & & & \\
\hline 7. M-C physical & .12 & .11 & .07 & $.13 \mathrm{j}$ & .11 & .40 & - & & & & & & & & & & \\
\hline 8. M overreactivity & .11 & .16 & .03 & .21 & .24 & .43 & .36 & - & & & & & & & & & \\
\hline 9. M-F emotional & .00 & .01 & .00 & .25 & .08 & .30 & .29 & .37 & - & & & & & & & & \\
\hline 10. M-F physical & .14 & .09 & .16 & .07 & .21 & .17 & .24 & .15 & .48 & - & & & & & & & \\
\hline hostility & .09 & .10 & .09 & .11 & .05 & .10 & .26 & .06 & .42 & .22 & - & & & & & & \\
\hline 12. F-C emotional & .04 & .06 & .05 & .10 & .18 & .32 & .21 & .35 & .52 & .22 & .20 & - & & & & & \\
\hline 13. F-C physical & -.06 & -.02 & -.09 & .14 & .09 & .28 & .34 & .24 & .32 & .27 & .23 & .36 & - & & & & \\
\hline 14. F overreactivity & .03 & -.02 & .11 & .36 & .14 & .21 & .20 & .25 & .27 & .06 & .27 & .36 & .29 & - & & & \\
\hline 15. F-M emotional & .03 & -.02 & .04 & .14 & -.05 & .22 & .21 & .11 & .50 & .36 & .33 & .28 & .17 & .19 & - & & \\
\hline $\begin{array}{l}\text { 16. F-M physical } \\
\text { 17. F observed }\end{array}$ & .15 & .10 & .14 & .16 & .23 & .25 & .23 & .12 & .48 & .71 & .26 & .30 & .24 & .12 & .40 & - & \\
\hline hostility & -.06 & .02 & -.13 & -.04 & .00 & .08 & .02 & .02 & .30 & .24 & .49 & .16 & .18 & .19 & .36 & .20 & - \\
\hline$M$ & 0.00 & 0.72 & 0.88 & 0.00 & 8.57 & 0.06 & 0.07 & 3.14 & 0.30 & 0.07 & 6.60 & 0.05 & 0.06 & 3.01 & 0.23 & 0.04 & 4.66 \\
\hline$S D$ & 0.86 & 1.26 & 0.07 & 0.74 & 3.25 & 0.10 & 0.08 & 1.12 & 0.45 & 0.26 & 7.64 & 0.12 & 0.08 & 0.89 & 0.42 & 0.16 & 7.35 \\
\hline Min & -1.89 & -1.73 & 0.71 & -1.09 & 2.67 & 0.00 & 0.00 & 1.00 & 0.00 & 0.00 & 0.00 & 0.00 & 0.00 & 1.00 & 0.00 & 0.00 & 0.00 \\
\hline Max & 2.07 & 3.52 & 1.05 & 2.08 & 21.25 & 0.38 & 0.39 & 7.00 & 2.22 & 1.93 & 35.94 & 0.50 & 0.39 & 5.60 & 2.11 & 1.29 & 34.85 \\
\hline
\end{tabular}


Table 2

Regression Models Relating Maternal and Paternal Hostility to Child Adiposity

$$
95 \% \mathrm{CI}
$$

$\beta \quad S E \quad p \quad$ Low High

\section{Model H1 M}

Mother-to-child hostility

$$
.26
$$

$0.12 \quad .035$

.02

.50

Model H2

Mother-to-father hostility

$$
.11
$$

0.11

.293

$-.10$

.32

\section{Model E1M}

Mother-to-child hostility

$$
.26
$$

0.16

.099

$-.05$

.57

Mother-to-father hostility

$-.03$

0.15

.850

$-.32$

.27

\section{Model H1F}

Father-to-child hostility

0.13

.295

$-.11$

.38

\section{Model H2F}

Father-mother hostility

$\begin{array}{lll}.07 & 0.12 \quad .552\end{array}$

$-.17$ 


\section{Figure Captions}

Figure 1. Indirect effect model for mother-to-child hostility to child adiposity via child sugary drink consumption (Model $\left.\mathrm{H} 3.1_{\mathrm{M}}\right)$; coefficients are standardised regression coefficients and bootstrapped 95\% CIs (low, high).

Figure 2. Interaction of mother-to-father (top) and mother-to-father (bottom) hostility and child gender. 


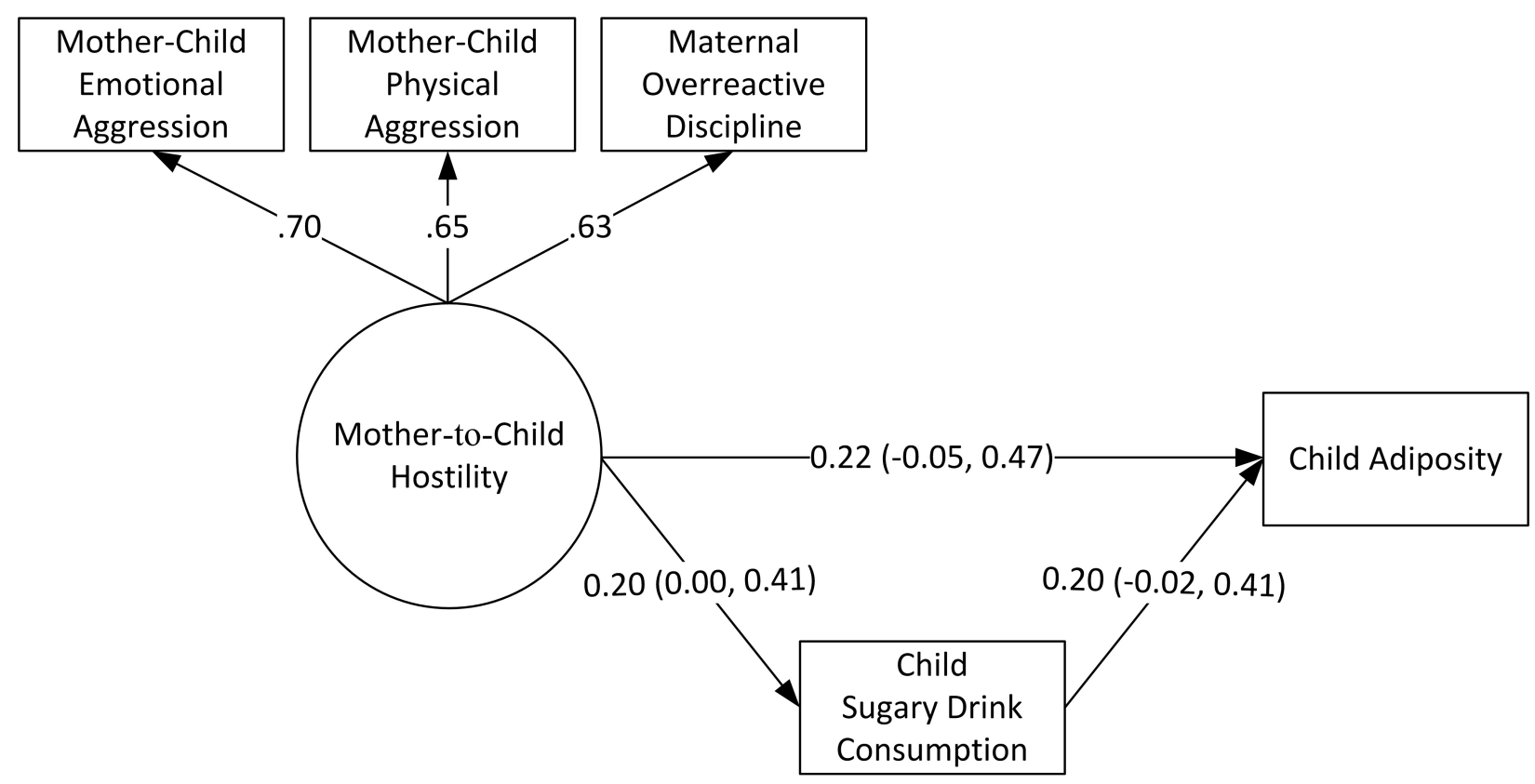



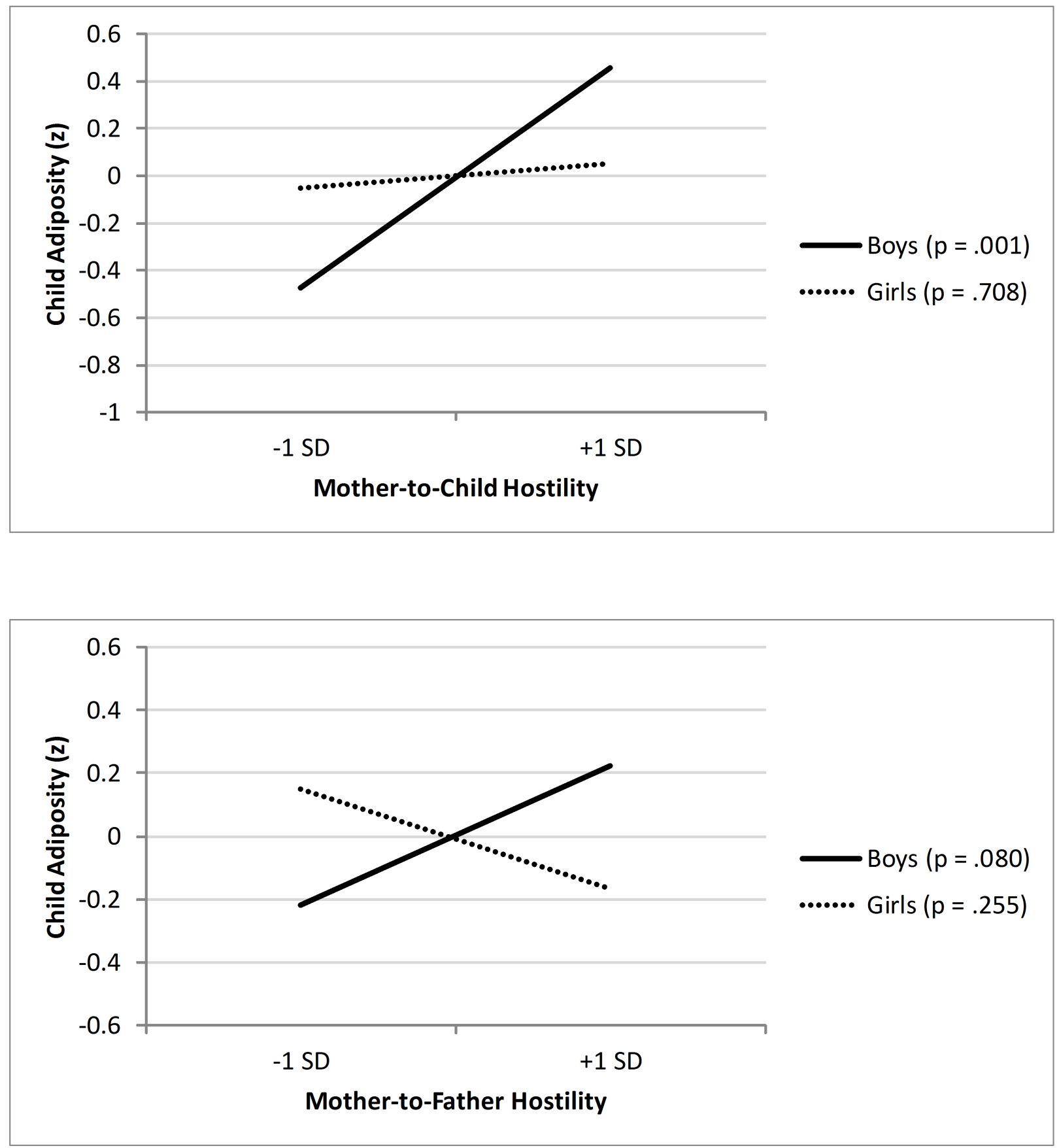
ON-LINE SUPPLEMENT: The relations of child adiposity with parent-to-child and parent-toparent hostility

This supplement contains information regarding the statistical models.

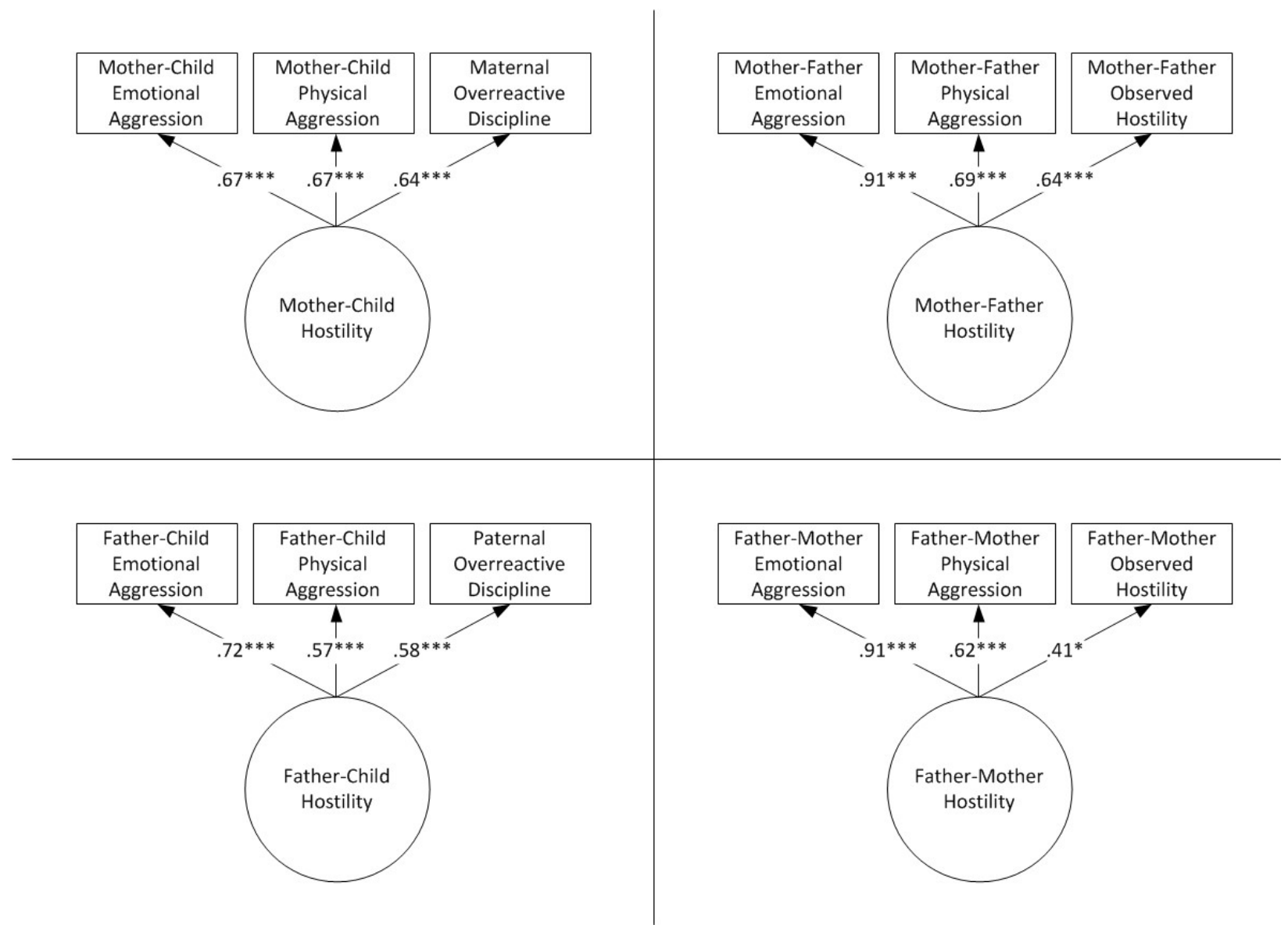

Figure S1. Measurement models; standardised estimates; just identified, thus no fit indices; ${ }^{*} p$ $<.05 . * * * p<.001$ 
ON-LINE SUPPLEMENT: The relations of child adiposity with parent-to-child and parent-toparent hostility

MODEL H1 $1_{\mathrm{M}}$

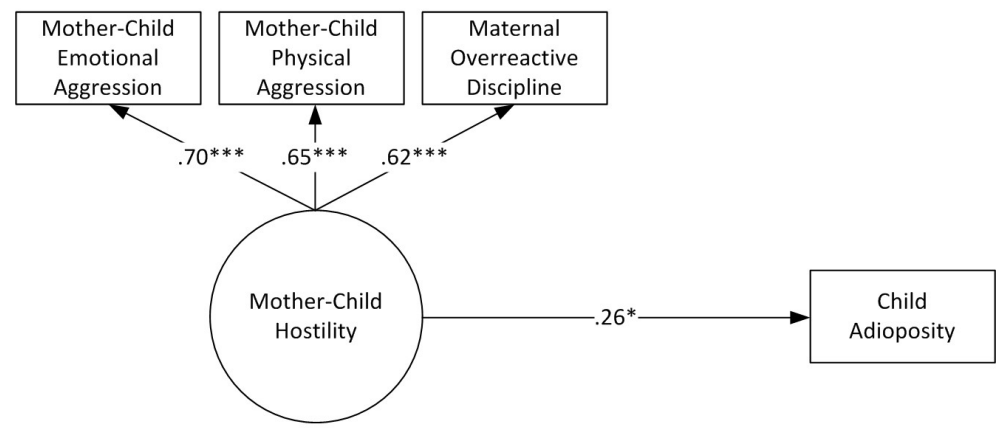

MODEL H2 $2_{M}$

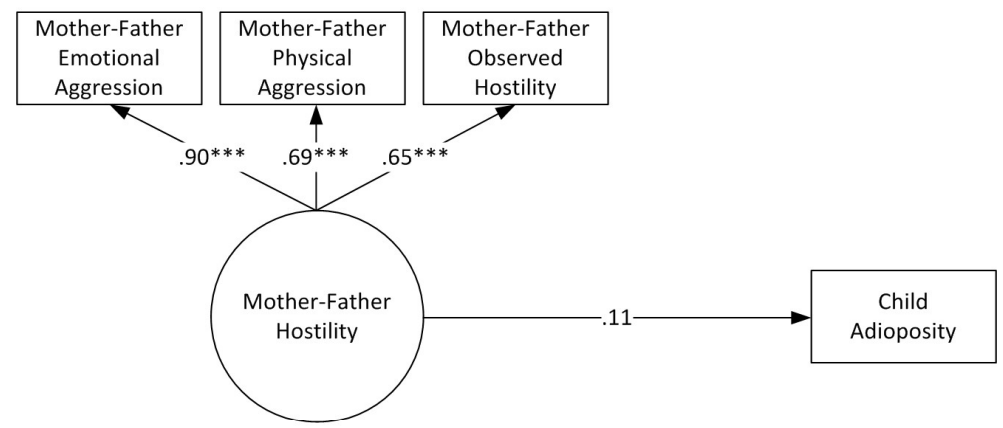

MODEL E1 $1_{M}$

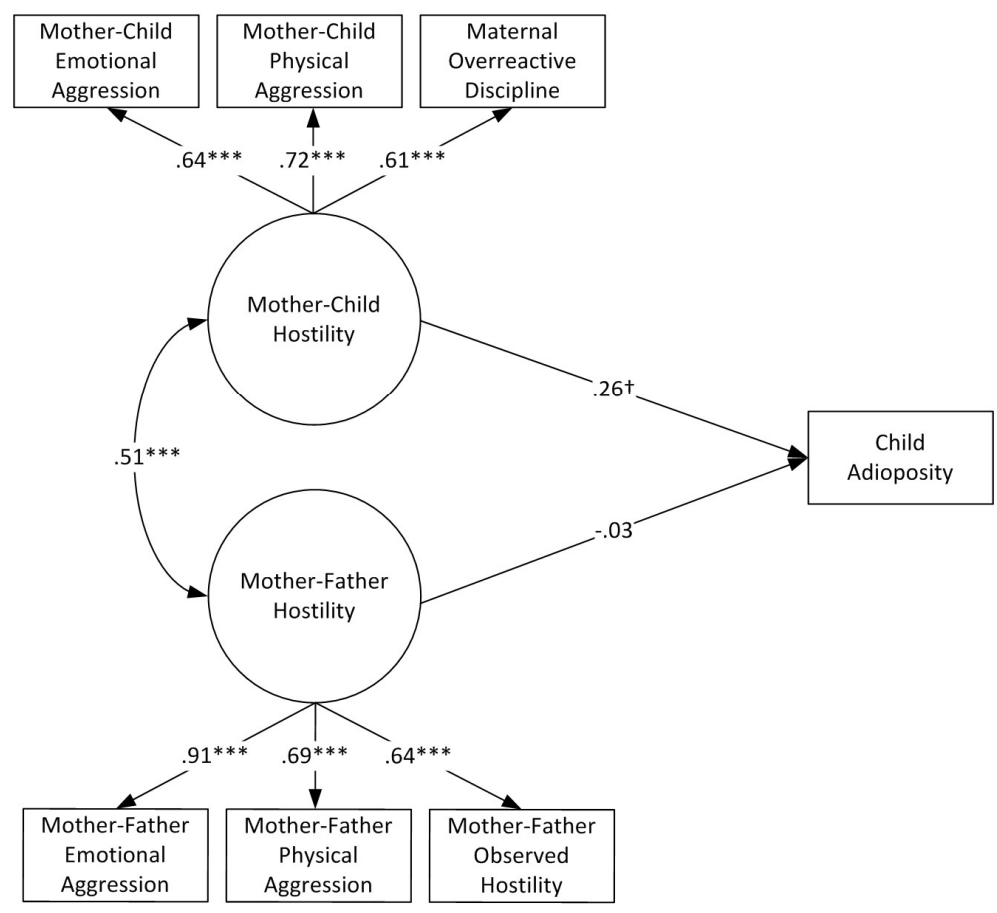

Figure S2. Child adiposity in relation to maternal hostility; standardised estimates; $\uparrow p<.10 .{ }^{*} p$ $<.05 . * * p .01 . * * * p<.001$. 
ON-LINE SUPPLEMENT: The relations of child adiposity with parent-to-child and parent-toparent hostility

MODEL H1 $1_{\text {F }}$

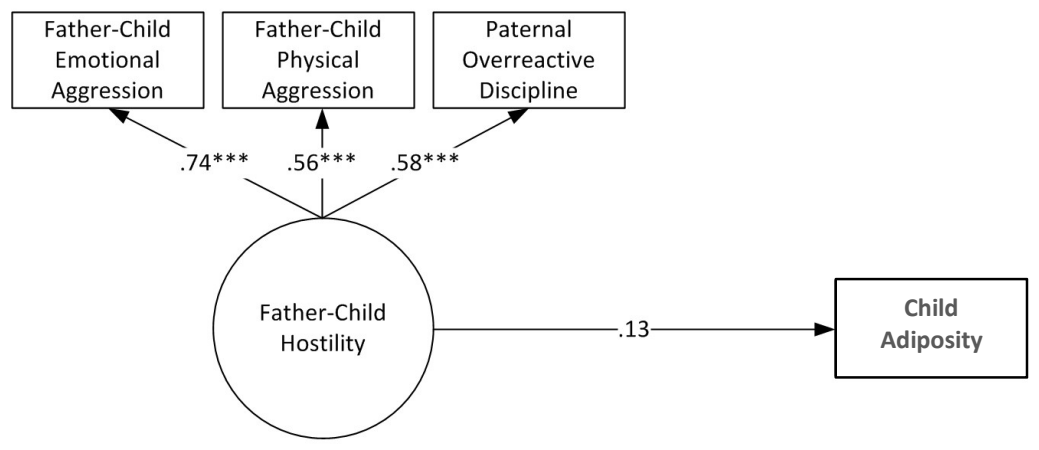

MODEL H2

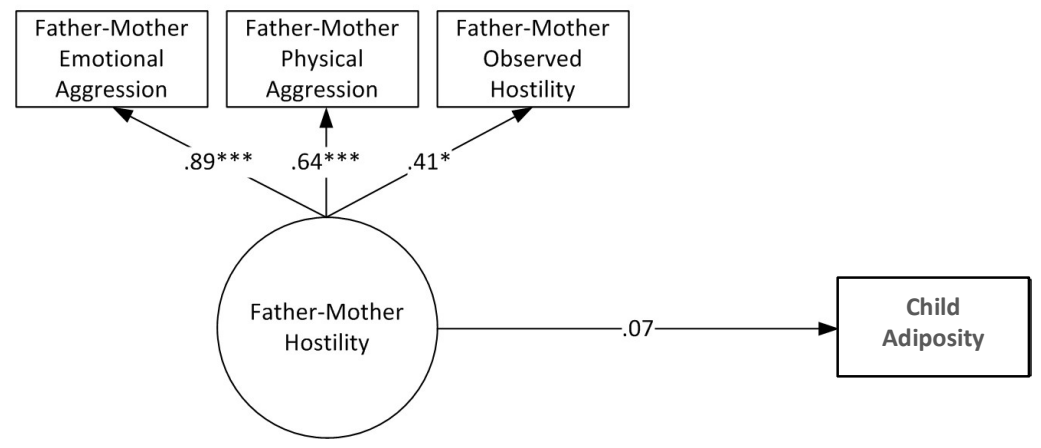

Figure S3. Child adiposity in relation to paternal hostility; standardised estimates; ${ }^{*} p<.05 .{ }^{* * *} p$ $<.001$. 
ON-LINE SUPPLEMENT: The relations of child adiposity with parent-to-child and parent-toparent hostility

Table S1

Model Fit

\begin{tabular}{|c|c|c|c|c|c|}
\hline Model Number & $\chi^{2}$ & $d f$ & CFI & TLI & RMSEA \\
\hline $\mathrm{H} 1_{\mathrm{M}}$ & 4.10 & 2 & 0.97 & 0.90 & 0.09 \\
\hline $\mathrm{H} 2_{\mathrm{M}}$ & 1.30 & 2 & 1.00 & 1.02 & 0.00 \\
\hline $\mathrm{H} 1_{\mathrm{F}}$ & 1.12 & 2 & 1.00 & 1.06 & 0.00 \\
\hline $\mathrm{H} 2 \mathrm{~F}$ & 1.86 & 2 & 1.00 & 1.01 & 0.00 \\
\hline $\mathrm{E} 1_{\mathrm{M}}$ & 21.46 & 12 & 0.95 & 0.91 & 0.08 \\
\hline $\mathrm{H} 3.1_{\mathrm{M}}$ & 4.11 & 4 & 1.00 & 1.00 & 0.02 \\
\hline $\mathrm{H} 3.2 \mathrm{M}$ & 4. 93 & 4 & 1.00 & 1.00 & 0.03 \\
\hline $\mathrm{E} 2_{\mathrm{M}, \mathrm{C}}$ & 7.54 & 9 & 1.00 & 1.00 & 0.00 \\
\hline $\mathrm{E} 2_{\mathrm{M}, \mathrm{U}}$ & 2.96 & 8 & 1.00 & 1.00 & 0.00 \\
\hline $\mathrm{E} 3_{\mathrm{M}, \mathrm{C}}$ & 10.92 & 9 & 0.99 & 0.98 & 0.06 \\
\hline $\mathrm{E} 3{ }_{\mathrm{M}, \mathrm{U}}$ & 7.39 & 8 & 1.00 & 1.00 & 0.00 \\
\hline $\mathrm{E} 4.1_{\mathrm{M}, \mathrm{C}}$ & 8.19 & 14 & 1.00 & 1.00 & 0.00 \\
\hline $\mathrm{E} 4.1_{\mathrm{M}, \mathrm{U}}$ & 8.11 & 12 & 1.00 & 1.00 & 0.00 \\
\hline $\mathrm{E} 4.2_{\mathrm{M}, \mathrm{C}}$ & 9.62 & 14 & 1.00 & 1.00 & 0.00 \\
\hline $\mathrm{E} 4.2 \mathrm{M}, \mathrm{U}$ & 6.35 & 12 & 1.00 & 1.00 & 0.00 \\
\hline $\mathrm{E} 5.2 \mathrm{M}, \mathrm{C}$ & 10.73 & 14 & 1.00 & 1.00 & 0.00 \\
\hline $\mathrm{E} 5.2 \mathrm{M}, \mathrm{U}$ & 9.71 & 12 & 1.00 & 1.00 & 0.00 \\
\hline $\mathrm{E} 5.1_{\mathrm{M}, \mathrm{C}}$ & 14.19 & 14 & 1.00 & 1.00 & 0.02 \\
\hline $\mathrm{E} 5.1_{\mathrm{M}, \mathrm{U}}$ & 12.71 & 12 & 1.00 & 0.99 & 0.03 \\
\hline $\mathrm{E} 2_{\mathrm{F}, \mathrm{C}}$ & 7.72 & 11 & 1.00 & 1.00 & 0.00 \\
\hline $\mathrm{E} 2_{\mathrm{F}, \mathrm{U}}$ & 7.31 & 10 & 1.00 & 1.00 & 0.00 \\
\hline $\mathrm{E} 3_{\mathrm{F}, \mathrm{C}}$ & 12.63 & 11 & 0.97 & 0.97 & 0.05 \\
\hline $\mathrm{E} 3_{\mathrm{F}, \mathrm{U}}$ & 10.77 & 10 & 0.99 & 0.99 & 0.04 \\
\hline
\end{tabular}

Note. $\chi^{2}$ is Satorra-Bentler scaled (robust) $\chi^{2}$; CFI = Comparative Fit Index; TLI = Tucker-Lewis Fit Index; RMSEA = Root Mean Square Error Approximation; CFA = confirmatory factor analysis; $\mathrm{H}=$ hypothesis; $\mathrm{E}=$ exploratory; $\mathrm{M}=$ mother; $\mathrm{F}=$ father; $\mathrm{C}=$ constrained; $\mathrm{U}=$ unconstrained. 